\title{
Osteomielitis crónica de calcáneo: reporte de un caso y revisión de la literatura
}

\section{Chronic osteomyelitis of calcaneus: a case report and literature review}

\author{
Yessica Paola Alba Gutiérrez, * Margarita Hernández Mirelesł \\ *Residente de 4to año de Traumatología y Ortopedia; ${ }^{\ddagger}$ Médico adscrito al Servicio de Pie y Tobillo. \\ Centenario Hospital Miguel Hidalgo, Aguascalientes, México.
}

\begin{abstract}
Resumen
Se presenta el caso de un hombre de 38 años en el Centenario Hospital Miguel Hidalgo, Aguascalientes, México, con un cuadro de úlcera crónica en el talón derecho de cinco años de evolución posterior a traumatismo directo con objeto punzante en el talón involucrado, con antecedente de avance de colgajo hace cinco años. A la exploración clínica con pérdida cutánea de $7 \times 5 \mathrm{~cm}$ con exudado purulento y a la exploración radiológica se pone de manifiesto una imagen de hipotrofia de calcáneo derecho con restos óseos esclerosados y datos sugestivos de osteomielitis crónica. Tras una primera intervención con espaciador de cemento de polimetilmetacrilato + gentamicina con técnica de cadena y legrado de calcáneo, así como toma de cultivo, se confirma el diagnóstico con aislamiento de la lesión de Escherichia coli y Enterococcus faecalis mas rechaza el espaciador, por lo que se interviene de nueva ocasión para la resección de calcáneo. Al cicatrizar la herida se indica órtesis de pie-tobillo y se inicia la marcha sin dolor, y sin recidiva de la osteomielitis.
\end{abstract}

Palabras clave: Osteomielitis, calcáneo, cadena de polimetilmetacrilato.

\begin{abstract}
We present the case of a 38-year-old male patient at the Miguel Hidalgo Hospital Centenario, Aguascalientes, Mexico, with a five-year history of chronic ulcer on the right heel after direct trauma with a sharp object to the involved heel, with history of flap advancement five years ago. Clinical examination with $7 \times 5 \mathrm{~cm}$ skin loss with purulent exudate and radiological examination revealed an image of hypotrophy of the right calcaneus with sclerosed bone remains and data suggestive of chronic osteomyelitis. After a first intervention with a polymethylmethacrylate + gentamicin cement spacer with a chain technique and calcaneal curettage, as well as taking a culture, the diagnosis was confirmed with isolation of the Escherichia coli lesion and Enterococcus faecalis, but the spacer was rejected, he intervenes again for calcaneal resection. When the wound heals, ankle foot orthosis is indicated and walking is started without pain, and without recurrence of osteomyelitis.
\end{abstract}

Keywords: Osteomyelitis, calcaneus, polymethylmethacrylate chain.

\section{Introducción}

Una osteomielitis se define etimológicamente como una inflamación del hueso y de su médula, haciendo una diferencia la mayoría de los autores entre la osteítis como proceso que afecta principalmente al hueso, siendo de origen postraumático o postquirúrgico por contaminación directa, y las osteomielitis como proceso que produce una afectación ósea y medular debido a un mecanismo vascular, pudiendo ser por contaminación a distancia o metastásica. ${ }^{1}$

El concepto de osteomielitis no está consensuado de manera unánime y con base en la clínica es definido como una necrosis ósea por infección con afectación de partes blandas, caracterizado por exacerbaciones intermitentes, de larga duración y con una respuesta parcial al tratamiento antibiótico, mientras que otros autores lo definen por su tiempo

\section{Correspondencia:}

Yessica Paola Alba Gutiérrez

E-mail: alba.gutierrez08@hotmail.com

Recibido: 07-06-2021. Aceptado: 10-07-2021.

Citar como: Alba GYP, Hernández MM. Osteomielitis crónica de calcáneo: reporte de un caso y revisión de la literatura. Orthotips. 2022; 18 (1): 72-79. https://dx.doi.org/10.35366/103736 
de evolución, considerando la existencia de una osteomielitis crónica cuando una infección ósea no se ha curado tras un periodo de tratamiento de cuatro a seis semanas con independencia de su origen. En algunos casos la osteomielitis puede debutar inicialmente como crónica, sin periodo agudo previo.

La localización más habitual de las osteomielitis crónicas es a nivel de tibia, fémur y húmero y en los casos de origen postraumático o postquirúrgico allí donde se haya producido la lesión, siendo infrecuente la localización en calcáneo, mandíbula, trocánter mayor, etcétera. ${ }^{1}$

Dentro de las osteomielitis crónicas existe una forma conocida como osteomielitis esclerosante de Garré, en la que el hueso se engruesa y distiende formando una gran esclerosis, pero sin contener abscesos ni secuestros, y aunque se desconoce su etiología se presupone que es una infección debida a una bacteria de baja virulencia que podría ser anaerobia, aunque por lo general los cultivos suelen ser negativos y la biopsia sólo evidencia una osteomielitis crónica de bajo grado. Esta lesión debe diferenciarse del osteoma osteoide, así como de la enfermedad de Paget por su actividad ósea esclerosante. ${ }^{1,2}$

De acuerdo con la clasificación más aceptada actualmente para definir la osteomielitis, se debe mencionar aquella propuesta por Cierny y Mader, la cual toma como referencia una clasificación anatómica y otra fisiológica (Tabla 1). ${ }^{3}$

La localización de una osteomielitis a nivel del calcáneo es poco frecuente y debido a ello no siempre es incluido dentro del diagnóstico diferencial

Tabla 1: Clasificación de Cierny y Mader para osteomielitis.

Anatómica

\begin{tabular}{|c|c|}
\hline I Medular & Endosteal \\
\hline II Superficial & Superficie cortical infectada por falta de cobertura \\
\hline III Localizada & $\begin{array}{l}\text { Secuestro cortical que puede debridarse sin } \\
\text { comprometer estabilidad }\end{array}$ \\
\hline IV Difusa & $\begin{array}{l}\text { Cualquiera de las anteriores más inestabilidad } \\
\text { mecánica antes o después del desbridamiento }\end{array}$ \\
\hline
\end{tabular}

Fisiológico

\begin{tabular}{|c|c|}
\hline A Normal & Inmunocompetente con buena vascularidad \\
\hline B Comprometido & $\begin{array}{l}\text { Factores locales }(L) \text { o sistémicos }(S) \text { que } \\
\text { comprometen la inmunidad o cicatrización }\end{array}$ \\
\hline C Prohibitivo & $\begin{array}{l}\text { Discapacidad mínima, morbilidad grave, mal } \\
\text { pronóstico de curación }\end{array}$ \\
\hline
\end{tabular}

de las lesiones líticas de calcáneo, pudiendo ser el mecanismo por una infección hematógena, como complicación postquirúrgica, o bien, por inoculación directa. Asimismo, se habla de que en este tipo de osteomielitis, así como de cualquier hueso del tarso, son autolimitadas gracias al grueso periostio que no permite el paso de pus a otros espacios. ${ }^{2}$

La osteomielitis crónica de calcáneo es una complicada y retante enfermedad que representa de 3 a $11 \%$ de todas las infecciones óseas. Está muy limitada en su tratamiento, dado que en casi todas las ocasiones se trata de una osteomielitis con defectos para la cobertura cutánea, asimismo por la pobre irrigación a este hueso, lo que debilita el tratamiento sistémico antimicrobiano. El tratamiento definitivo siempre será tratando de mantener todas las estructuras posibles y la mayor función del pie posible. Sin embargo, es una patología con gran tasa de fallo y que puede llegar incluso a la amputación de la extremidad.

La osteomielitis del calcáneo puede ocurrir en varias situaciones clínicas donde la infección se introduce de manera endógena mediante siembra hematógena, diseminación contigua de bacterias desde sitios de infección adyacentes o exógenamente por trauma, complicaciones quirúrgicas o heridas abiertas. La osteomielitis crónica de calcáneo por vía hematógena se asocia típicamente con pacientes pediátricos que desarrollan bacteriemia sistémica que conduce a la implantación de bacterias a través de la reducción del flujo sanguíneo en la epífisis del calcáneo. Mientras que en el paciente adulto es más a menudo el resultado de una infección contigua o exógena. ${ }^{3}$

Hasta $60 \%$ de las fracturas abiertas del calcáneo se infectan. En casos sometidos a intervención quirúrgica por calcáneo las fracturas tienen un mayor riesgo de desarrollar osteomielitis crónica, en particular aquéllos que requieren un abordaje lateral extendido tienen $27 \%$ de posibilidades de necrosis de la piel a lo largo de la incisión quirúrgica. El tejido necrótico en las incisiones quirúrgicas potencialmente retrasa la curación, aumentando la infección postoperatoria y ocurrencia de osteomielitis crónica. Las inoculaciones o pinchazos en la planta del pie son lesiones relativamente frecuentes y en ocasiones no se les suele dar la importancia que se merecen, Fitzgerald y Cowan en 1975 calcularon que $18 \%$ de las inoculaciones directas en la planta del pie progresan hasta una osteomielitis crónica; incluso se han descrito casos de osteomielitis crónica de calcáneo debido a las punciones que se realizan en los neonatos en el talón para las pruebas endócrinas. ${ }^{3}$ 
La presentación más frecuente de osteomielitis crónica es en el contexto de una ulceración crónica secundaria a trastornos neurológicos o complicaciones de presión. La neuropatía diabética periférica es un principal factor de riesgo para el desarrollo de una ulceración crónica. En el entorno hospitalario, la presión sostenida que conduce a úlceras de decúbito en el talón es una etiología común en el desarrollo de osteomielitis crónica de calcáneo. Las ulceraciones de decúbito en la zona del calcáneo son las segundas más comunes por presión y comprenden de 19 a $32 \%$ de ellas. ${ }^{2,4}$

La integridad estructural y los tejidos blandos adyacentes son consideraciones importantes con respecto al tratamiento médico o quirúrgico de la osteomielitis crónica de calcáneo. El calcáneo se compone principalmente de hueso esponjoso con una capa externa cortical delgada. La competencia mecánica de un hueso depende del grosor y de la sección transversal de la capa externa cortical más densa. La ruptura de la capa cortical delgada predispone al calcáneo a la infección una vez que las bacterias se infiltran en la vascularización subyacente de hueso esponjoso. Las fuerzas reactivas del suelo aumentan hasta 1.5 veces el peso corporal de una persona con deambulación normal, lo que aumenta el estrés en el calcáneo. ${ }^{4}$

Ciertos factores han demostrado una forma más favorable o desfavorable para el pronóstico de este padecimiento. Los pacientes jóvenes y sanos con osteomielitis crónica de calcáneo tienen mayor posibilidad de recuperarse. ${ }^{4}$ En la Tabla 2 se muestran los factores involucrados en el pronóstico de la enfermedad.

El organismo aislado más común en osteomielitis crónica de calcáneo es Staphylococcus aureus; sin embargo, la ruta de inoculación puede predisponer el calcáneo a ciertas bacterias. En niños menores de dos años, Haemophilus influenzae se ve comúnmente a través de la siembra hematógena. Las infecciones polimicrobianas se observan en adultos mediante orígenes contiguos o exógenos, más importante cuando es secundario a complicaciones debido a ulceración crónica versus una lesión traumática, el riesgo de infección con especies gramnegativas y Pseudomonas aeruginosa se incrementa. El conocimiento de la ruta de inoculación puede ayudar en la selección de antibióticos. ${ }^{4}$

El estándar de oro para una osteomielitis crónica en general debe realizarse mediante toma de cultivo óseo o de tejido blando que rodea la lesión. ${ }^{5}$ Además,
Tabla 2: Factores pronósticos de osteomielitis crónica de calcáneo.

\begin{tabular}{ll}
\hline Favorables & Desfavorables \\
\hline ASA $<2$ & ASA $>2$ \\
Ausencia de neuropatía periférica & Presencia de neuropatía periférica \\
Ausencia de diabetes mellitus & \\
Edad & \\
Osteomielitis postraumática & \\
\hline
\end{tabular}

ASA = American Society of Anesthesiologists .

se debe analizar la clínica verificando la integridad de la piel y tejidos blandos, áreas de inestabilidad y estado neurovascular de la extremidad. Respecto a los estudios laboratoriales, no son específicos de la osteomielitis ni determinan el grado de severidad, incluso la leucocitosis sólo se puede manifestar en $35 \%$ de los casos. Los reactantes de fase aguda, velocidad de sedimentación globular y proteína $C$ reactiva, pudiesen ayudar al diagnóstico; sin embargo, su negatividad no descarta el proceso infeccioso. Por último, en estudios de imagen se habla de lesiones patognomónicas de osteomielitis determinadas por secuestro óseo, lesiones líticas y, en sus fases terminales, esclerosis del hueso afectado. ${ }^{3,5}$

Las radiografías son a menudo la primera modalidad de imagen utilizada en el diagnóstico de osteomielitis. Los hallazgos radiográficos asociados con la etapa aguda de la osteomielitis incluyen inflamación de los tejidos blandos, formación de hueso subperióstico y/o localización de pérdida de densidad ósea. Entre 30 y $60 \%$ de la desmineralización ósea debe ocurrir antes de que se presente evidencia radiográfica aparente, lo que puede retrasar ciertos hallazgos por 10 a 14 días, como la formación de secuestro, involucrum o ver cloacas durante la etapa crónica. ${ }^{6}$

El tratamiento de erradicación debe ser un desbridamiento quirúrgico agresivo, con manejo del espacio muerto (relleno con injerto óseo autólogo o espaciadores de cemento de polimetilmetacrilato con gentamicina en técnica de bloque o de cadena) y tratamiento antimicrobiano oral o intravenoso, lo cual en la mayoría de los casos es determinante para la erradicación del proceso. El tratamiento está influenciado por una combinación de los deseos del paciente, preferencia del cirujano y factores locales como la disponibilidad de cobertura de tejidos blandos y el estado vascular. ${ }^{3}$ La terapia con antibióticos debe determinarse por el cultivo y los resultados de 
susceptibilidad. En ausencia de esta información, la terapia empírica de amplio espectro puede basarse en la ruta de infección, edad del paciente y/o duración de la enfermedad. Sin embargo, para una mejor administración de antibióticos, la terapia debe adaptarse a los organismos aislados específicos. ${ }^{5}$ La duración depende del objetivo del régimen de tratamiento y ubicación anatómica de la infección. En la osteomielitis aguda, que se define como infección diagnosticada dentro de dos semanas de inicio y localizadas en el canal medular, la terapia con antibióticos puede ser suficiente como el único tratamiento para erradicar la infección. Históricamente, el antibiótico parenteral se ha administrado como terapia de cuatro a seis semanas durante el tratamiento de osteomielitis. ${ }^{2}$

El tratamiento quirúrgico por lo general está indicado si la terapia con antibióticos ha fallado o depende de los deseos del paciente. La intervención varía desde desbridamiento del calcáneo con o sin rotación del colgajo para el cierre de la herida, calcanectomía parcial o total, o amputación proximal. ${ }^{7}$ Gaenslen describió la calcanectomía parcial en 1931 como un procedimiento que divide el calcáneo en dos mitades para permitir la resección de hueso infectado. Autores adicionales han mostrado resultados exitosos con este procedimiento desde que se publicó su artículo. ${ }^{3,8}$

Antes de que cualquier paciente se someta a una intervención quirúrgica, se debe realizar una evaluación médica preoperatoria para identificar cualquier factor asociado con la disminución de los resultados quirúrgicos. ${ }^{7}$ Se observan mayores resultados quirúrgicos en individuos con índice tobillo-brazo $>0.45$, presión parcial transcutánea de oxígeno $>28 \mathrm{mmHg}$, y nivel de albúmina $>3.0 \mathrm{~g} / \mathrm{dl}$. Incluso con una pla-

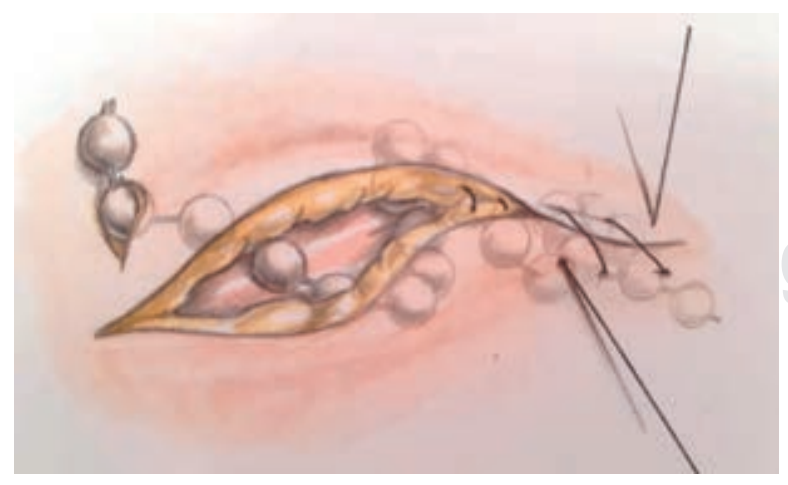

Figura 1: Técnica de introducción de cadena de polimetilmetacrilato con gentamicina.

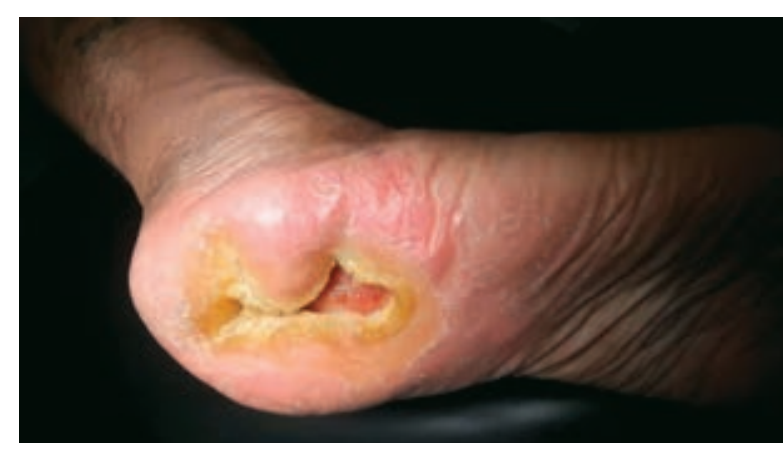

Figura 2: Imagen clínica de úlcera en talón en la primera visita del paciente a la consulta.

nificación preoperatoria óptima para preparar a los pacientes para la intervención quirúrgica, las complicaciones postquirúrgicas pueden ocurrir, dificultando la recuperación. 5,8

El empleo de bolas y cadenas de polimetilmetacrilato (PMMA) con gentamicina (Figura 1) tuvo como punto de partida las observaciones clínicas de Bucholtz y las investigaciones experimentales de Wahlig, quienes comprobaron que la asociación de gentamicina al cemento óseo constituía una medida de profilaxis y tratamiento de las infecciones en la cirugía de sustitución articular. Las ventajas de este método son: liberación retardada del antibiótico a alta concentración en el lugar de la infección, desaparición del espacio cavitario por el relleno con las bolas y proliferación de tejido conjuntivo y de granulación, evita utilizar el lavado continuo, posibilidad de prescindir del tratamiento por vía parenteral y acortamiento de la estancia en hospital y de gastos. ${ }^{9}$

Digeldein y Wahlig estudiaron la concentración de gentamicina en el suero $(>1 \mu \mathrm{g} / \mathrm{ml})$, en la orina $(10 \mu \mathrm{g} /$ $\mathrm{ml}$ ) y en el hematoma de la herida operatoria (50 a 80 $\mu \mathrm{g} / \mathrm{ml}$ ), en la cual la concentración mínima inhibitoria corresponde a los más importantes gérmenes, se halla entre los 0.5 a $4 \mu \mathrm{g} / \mathrm{ml} .8,9$

La resección de la tuberosidad del calcáneo se realiza en un ángulo oblicuo de 1 a $2 \mathrm{~cm}$ por detrás de la articulación subtalar. 6,7

\section{Presentación del caso}

Se presenta hombre de 38 años a la consulta clínica de pie y tobillo. Comerciante, soltero, escolaridad secundaria. No cuenta con antecedentes de enfermedades crónico degenerativas, toxicomanías positivas a múltiples drogas, sin mencionar cuáles. 


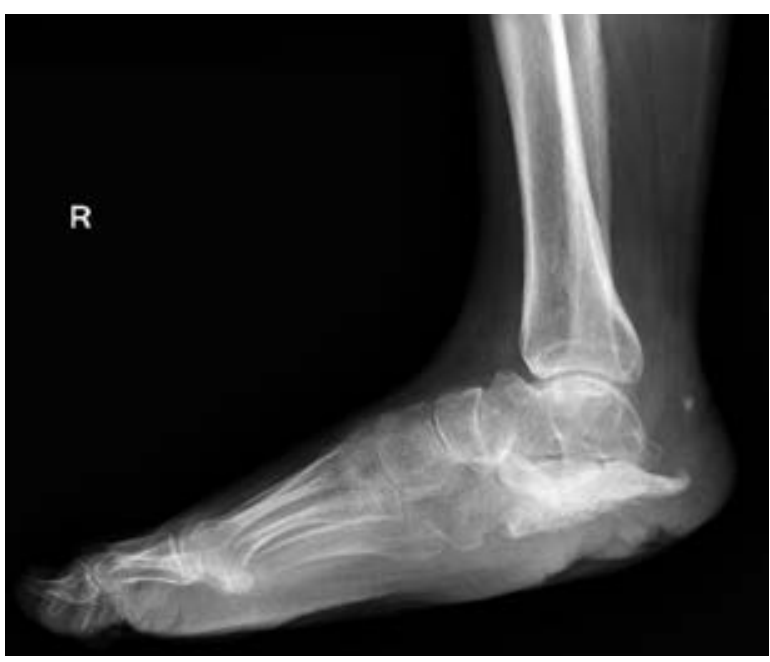

Figura 3: Radiografía lateral de pie derecho con imagen de calcáneo con osteomielitis.

Asimismo con antecedente de fractura de radio y cúbito izquierdo hace 14 años, fractura de fémur izquierdo en 2005. Menciona como padecimiento actual presencia de úlcera plantar de 10 años de evolución intervenida en una ocasión en 2015 por el Servicio de Cirugía Plástica con cierre de úlcera con avance de colgajo. Se reporta en expediente que vuelve dos años después con presencia de nuevo de úlcera, en esta ocasión de $5 \times 4 \times 4 \mathrm{~cm}$, limpia, con tejido de granulación, bordes macerados y húmedos por apoyo, por lo que se indican aseos diarios, aún por parte de cirugía plástica y es enviado a la consulta de pie y tobillo con resultados de resonancia magnética, manejándose con aseos diarios en casa.

Acude a la consulta de Traumatología y Ortopedia en primera ocasión en mayo de 2019 , ya con cuatro años de evolución con úlcera crónica (Figura 2), sin apoyo y con talalgia intensa. Pérdida cutánea, sin exudado ni datos de infección de la herida. Se solicitan radiografías anteroposterior (AP) y axial de calcáneo (Figura 3) , las cuales lleva a la próxima consulta evidenciando datos de lisis ósea de calcáneo con pérdida de la morfología normal del hueso, el cual se observa radiolúcido en toda su extensión, con datos de esclerosis, pérdida de la altura de la parte posterior, con la articulación calcaneocuboidea íntegra, pérdida de la congruencia de la articulación subtalar. En resultado de resonancia magnética (Figura 4), además de lo mencionado en radiografías, se evidencian cambios inflamatorios a nivel del tendón de Aquiles, además de observar respetados el tarso y el astrágalo sin datos de lisis ósea o secuestros.

Es intervenido en junio de 2019, se le realiza aseo quirúrgico, disecando la úlcera ya presente de forma roma, ampliándola $1 \mathrm{~cm}$ hacia distal y otro hacia proximal, se llega a cara plantar de calcáneo encontrando como hallazgo tejido óseo escleroso, sin datos de infección activa, con abundante tejido fibrótico pericalcáneo, sangrante. Se realizó la técnica, se desbrida tejido de fibrosis y se retira tejido esclerótico de calcáneo con gubia y se irriga con 4 litros de solución fisiológica y otro impregnado con ámpula de gentamicina. Después se realizó la técnica

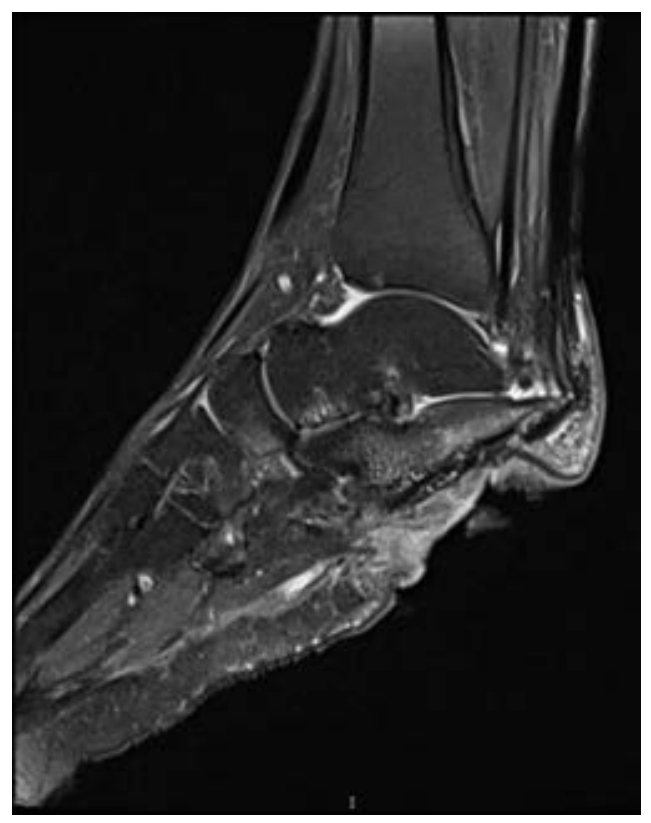

Figura 4: Resonancia magnética, corte sagital de pie derecho.

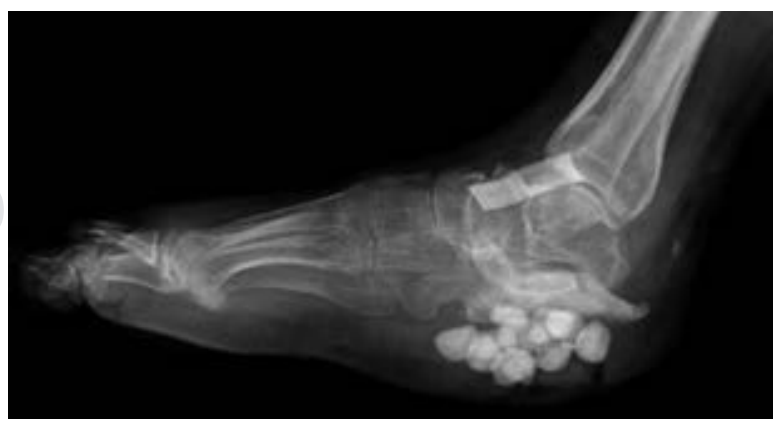

Figura 5: Radiografía lateral de pie derecho postquirúrgica de inserción de cadena de polimetilmetacrilato. 
de cadena de polimetilmetacrilato con gentamicina montado en Prolene, dejando la referencia de sutura por fuera de la piel (Figura 5) y se procedió a cerrar con puntos antitensionales. Se egresa el paciente sin complicaciones.

El sujeto reingresa al Servicio de Urgencias a los tres días postquirúrgicos refiriendo fiebre, herida quirúrgica dehiscente con exudado fétido y achocolatado (Figura 6). Se reportan así mismo en los laboratoriales leucocitosis de $10.1 \mathrm{mg} / \mathrm{dl}$, proteína $\mathrm{C}$ reactiva (PCR) $142 \mathrm{mg} / \mathrm{dl}$ y velocidad de sedimentación globular (VSG) $12 \mathrm{mg} / \mathrm{dl}$ y se inicia antibioticoterapia empírica con levofloxacino y amoxicilina por parte del Servicio de Infectología. Se realizó un aseo quirúrgico donde se retiró la cadena de polimetilmetacrilato con gentamicina y se afrontan bordes. Se egresa con levofloxacino y amoxicilina vía oral.

Reingresa el paciente a los 15 días, ya que se evidencia en laboratoriales de control aumento de reactantes de fase aguda con leucocitos de $5.3 \mathrm{mg} /$ dl, PCR $26 \mathrm{mg} / \mathrm{dl}$ y VSG $70 \mathrm{ml} / \mathrm{dl}$ y se realiza, en el mismo junio de 2019, resección de calcáneo; se realizó con abordaje lateral hasta la punta del maléolo, se desperiostizó evitando lesionar los tendones peroneos y el nervio sural, hasta llegar al hueso, se identificó la articulación subastragalina, en la cual se reporta tejido fibroso y adherencias, se proce-

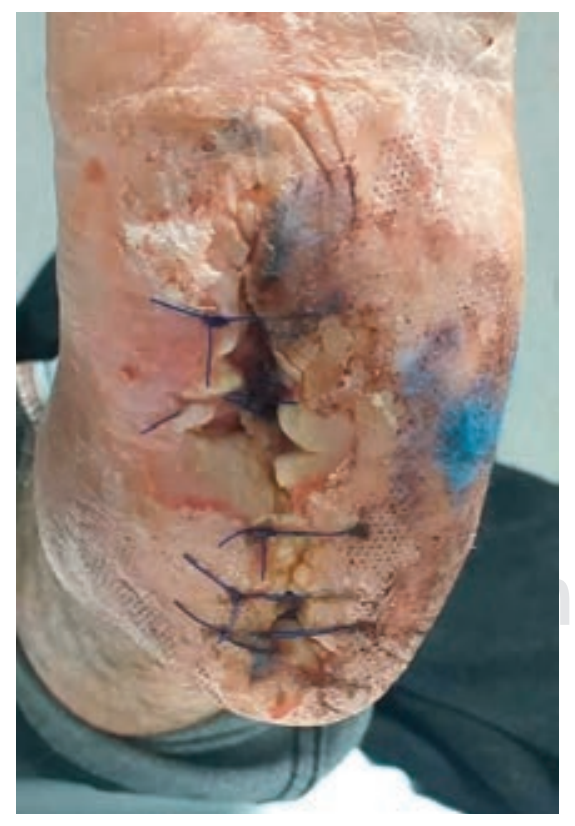

Figura 6: Imagen clínica de talón derecho al rechazo de la cadena de polimetilmetacrilato.

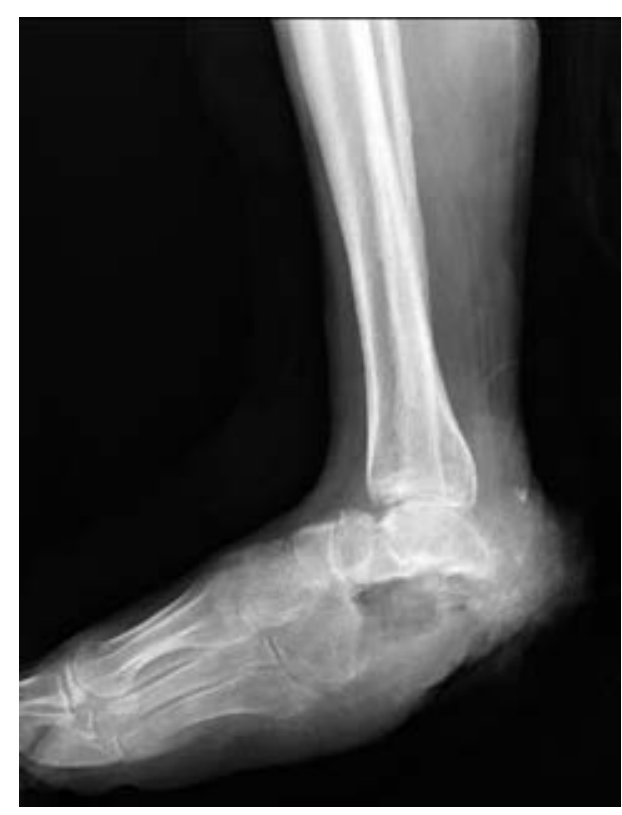

Figura 7: Radiografía lateral de pie derecho posterior al retiro de la cadena de polimetilmetacrilato.

dió a realizar osteotomía de calcáneo y resección (Figura 7). Se desbridó todo el tejido desvitalizado fibroso periférico, respetando tendón tibial posterior. Se retiró cartílago articular de la subastragalina, se desinsertó el tendón de Aquiles y se procedió a dar cierre a la herida. Se egresa y se da el mismo esquema antibiótico ambulatorio previamente utilizado. Se presenta el paciente en agosto de 2019 con laboratoriales de control PCR $3.5 \mathrm{mg} / \mathrm{dl}$, VSG $33 \mathrm{mg} / \mathrm{dl}$ y leucocitos $4.3 \mathrm{mg} / \mathrm{dl}$. Herida cicatrizada, sin exudado, sin datos de infección o dehiscencia (Figuras 8 y 9). En octubre de 2019, inicia el apoyo con órtesis de tobillo-pie, sin dolor.

\section{Discusión}

Se utilizó esta técnica como espaciador y con la intención de no volver a incidir sobre la herida ya abierta de cuatro años de evolución para retirar el espaciador por una herida donde se dejó la referencia. Probablemente el fallo se debió a la conservación del calcáneo esclerosado e infectado en su sitio, así como el espacio disminuido para su colocación.

Los laboratoriales, como se mencionó antes, no son determinantes como factores pronósticos o de gravedad; sin embargo, en este caso la proteína C reactiva y la velocidad de sedimentación globular 


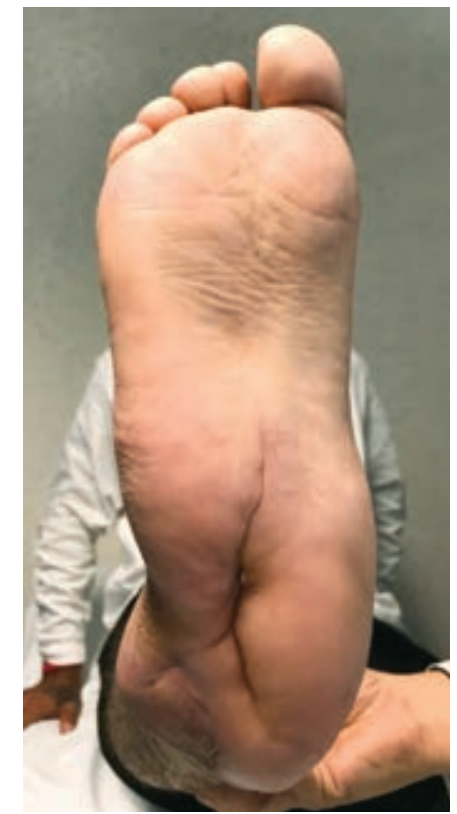

el único método resolutivo para la solución de un caso de osteomielitis crónica de calcáneo de cuatro años.

A los dos años de evolución, el paciente se encuentra con la herida cicatrizada, sin fístulas y dado de alta por parte del Servicio de Infectología, ya sin tratamiento antimicrobiano. Utiliza una órtesis de tobillo-pie con aumento en el talón y tiene marcha bipodálica con apoyo de andadera (Figuras 10 y 11).

\section{Conclusiones}

Los pinchazos o inoculaciones directos en la planta del pie son lesiones relativamente frecuentes

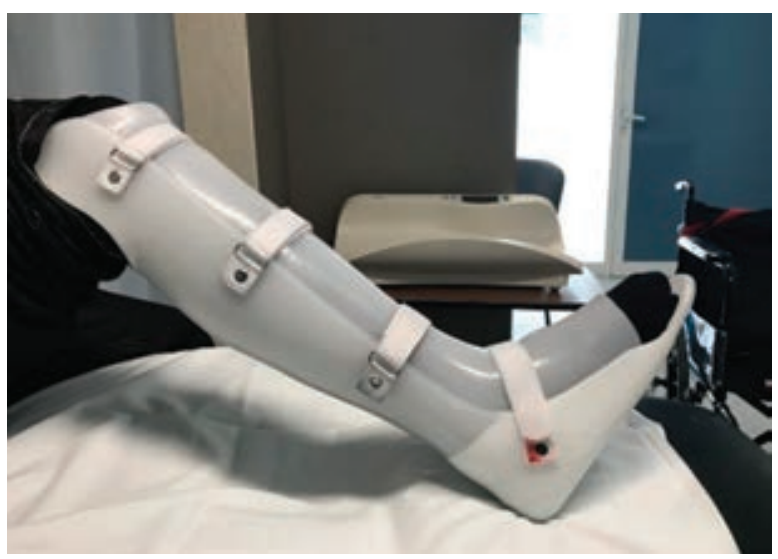

Figura 10: Órtesis de tobillo-pie.

Figura 9:

Imagen lateral de pie derecho actual.

fueron descendiendo según el tiempo de tratamiento antimicrobiano y, más drásticamente, posterior al tratamiento radical, por lo que determinamos que, en este caso, sí fueron concluyentes.

El tratamiento antimicrobiano tanto empírico como basado en los resultados del cultivo se presentan como efectivos al contribuir a la curación de la osteomielitis. ${ }^{1}$ Sin embargo, está claro que el tratamiento agresivo mediante resección radical del calcáneo fue

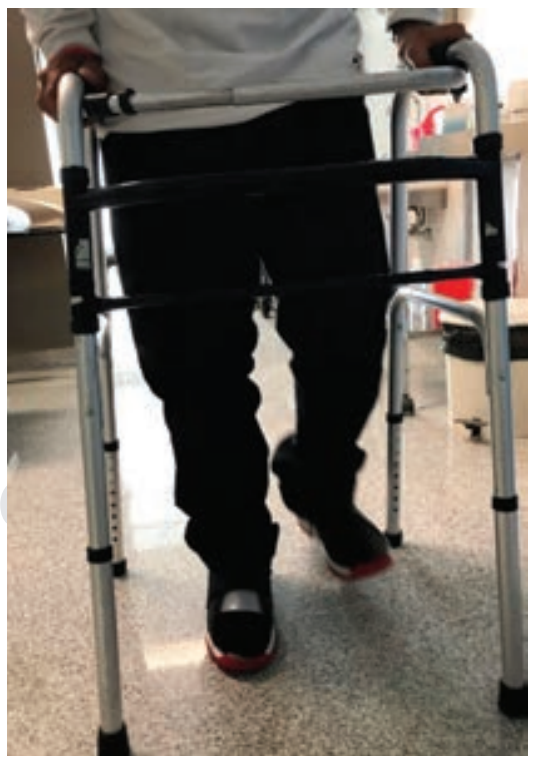

Figura 11: Deambulación actual bipodálica con apoyo de andadera. 
y un gran porcentaje de casos suelen acudir a un centro sanitario, deberíamos realizar una evaluación inicial de la zona lesionada, de la profundidad de la inoculación, del objeto causante de la misma, etcétera, además de realizar un estudio radiológico para descartar la existencia de cuerpos extraños radiopacos, así como explorar la herida en busca de aquellos materiales radiolúcidos. ${ }^{2}$

El problema reside en aquellos casos en los que, por falta de atención sanitaria inicial o por propio progreso del proceso, se produce la evolución hacia la osteomielitis crónica, dando lugar a la aparición de lesiones líticas en la radiología que debido a lo inusual del caso no suelen formar parte del diagnóstico diferencial inicial de las lesiones líticas de calcáneo, lo cual genera una confusión etiológica de la lesión. ${ }^{1}$ Es por ello que consideramos útil incluir a la osteomielitis crónica como posible causa de lesiones líticas de calcáneo, a pesar de no recogerse en la anamnesis inicial la existencia de antecedentes traumáticos 0 quirúrgicos de la zona, pues como hemos comprobado, basta una simple inoculación accidental, que suele pasar inadvertida para el paciente, para llegar a desarrollar una osteomielitis crónica de calcáneo. ${ }^{10}$

Se ha demostrado a lo largo de los años que las toxicomanías empobrecen el buen pronóstico de un paciente con osteomielitis, ya que es causa de inmunosupresión. Por lo tanto, la mala evolución de este caso en concreto podría relacionarse con sus antecedentes. Asimismo, el tiempo de evolución entre el inicio de los síntomas y su atención especializada no permitieron que se le ofreciera algún otro tipo de tratamiento y el que se intentó de rescate con perlas de polimetilmetacrilato fue fallido dada la evolución crónica y tórpida del proceso infeccioso. La osteomielitis de calcáneo es una grave complicación en la que es esencial un desbridamiento radical de todo el tejido necrótico, desvitalizado e infectado, utilizando los mismos criterios que en la cirugía oncológica. ${ }^{11}$

La biomecánica y la fuerza de la extremidad inferior normal se pueden alterar a partir de la resección del tubérculo calcáneo que soporta peso y la eliminación de la inserción del tendón de Aquiles. Los músculos del compartimento posterior disminuyen su fuerza un grado muscular en pacientes después de calconectomías parciales pero normalmente se restaura una vez que el paciente obtiene la ortesis adecuada de tobillo-pie. La recuperación después de la calconectomía parcial o total puede ser compleja y se asocia con numerosas complicaciones; sin embargo, ofrece resultados favorables. En este caso en particular, ofrecerle calcanectomía total al paciente fue un procedimiento de salvataje del cual, de haber fallado, se hubiese propuesto la amputación infratuberositaria, por lo que consideramos exitosa la marcha con andadera, ya que el paciente fue capaz de mantener su extremidad puesto que expresó durante el tratamiento su deseo de mantenerla. ${ }^{6,7}$

\section{Referencias}

1. Revenga Giertych C, Carrascosa Cerquero A, Vela Panes T, Gutiérrez Nogueroles M. Osteomielitis crónica de calcáneo. A propósito de un caso. Rev S And Traum y Ort. 2002; 22 (1): 80-85.

2. Wang EH, Simpson S, Bennet GC. Osteomyelitis of the calcaneum. J Bone Joint Surg Br. 1992; 74 (6): 906-909.

3. McCann MJ, Wells A. Calcaneal osteomyelitis: current treatment concepts. Int J Low Extrem Wounds. 2020; 19 (3): 230-235.

4. Fleischer AE, Didyk AA, Woods JB, Burns SE, Wrobel JS, Armstrong DG. Combined clinical and laboratory testing improves diagnostic accuracy for osteomyelitis in the diabetic foot. J Foot Ankle Surg. 2009; 48 (1): 39-46.

5. Simon L, Gauvin F, Amre DK, Saint-Louis P, Lacroix J. Serum procalcitonin and $\mathrm{C}$-reactive protein levels as markers of bacterial infection: a systematic review and meta-analysis. Clin Infect Dis. 2004; 39 (2): 206-217.

6. Boffeli TJ, Collier RC. Near total calcanectomy with rotational flap closure of large decubitus heel ulcerations complicated by calcaneal osteomyelitis. J Foot Ankle Surg. 2013; 52 (1): 107-112.

7. Baravarian B, Menendez MM, Weinheimer DJ, Lowery C, Kosanovich R, Vidt L. Subtotal calcanectomy for the treatment of large heel ulceration and calcaneal osteomyelitis in the diabetic patient. J Foot Ankle Surg. 1999; 38 (3): 194-202.

8. Dalmau-Coll A, Morales-Montoya A, Ronda-Rivero F, Comellas-Alabern J. Osteomielitis postraumática del calcáneo: resultados de su tratamiento. Rev Esp Cir Ortop Traumatol. 2006; 50 (5): 378-381.

9. Cervello S, De la Concepción M, Albert L. El uso de las cadenas de PMMA- Gentamicina en el tratamiento de las infecciones en cirugía ortopédica y traumatología. Revista Española de Cirugía Articular. 1979; 14: 417-423.

10. Bollinger M, Thordarson DB. Partial calcanectomy: an alternative to below knee amputation. Foot Ankle Int. 2002; 23 (10): 927-932.

11. Baumhauer JF, Fraga CJ, Gould JS, Johnson JE. Total calcanectomy for the treatment of chronic calcaneal osteomyelitis. Foot Ankle Int. 1998; 19 (12): 849-855.

\section{Conflicto de intereses}

No cuenta con conflicto de intereses de ningún tipo. 